\title{
Potential evaporation estimation through an unstressed surface-energy balance and its sensitivity to climate change
}

\author{
A. Barella-Ortiz ${ }^{1,2}$, J. Polcher ${ }^{2,3, *}$, A. Tuzet ${ }^{4}$, and K. Laval ${ }^{1,2}$ \\ ${ }^{1}$ Université Pierre et Marie Curie, Paris (Jussieu), France \\ ${ }^{2}$ Laboratoire de Météorologique Dynamique du CNRS, UMR8539, CNRS - IPSL, France \\ ${ }^{3}$ Centre National de la Recherche Scientifique, CNRS, France \\ ${ }^{4}$ Institut National de la Recherche Agronomique, INRA, France \\ * now at: Institut Català de Ciències del Clima, IC3, Spain
}

Correspondence to: A. Barella-Ortiz (anais.barella-ortiz@lmd.jussieu.fr)

Received: 5 May 2013 - Published in Hydrol. Earth Syst. Sci. Discuss.: 26 June 2013

Revised: 19 September 2013 - Accepted: 14 October 2013 - Published: 22 November 2013

\begin{abstract}
Potential evaporation $\left(\mathrm{ET}_{\mathrm{P}}\right)$ is a basic input for many hydrological and agronomic models, as well as a key variable in most actual evaporation estimations. It has been approached through several diffusive and energy balance methods, out of which the Penman-Monteith equation is recommended as the standard one. In order to deal with the diffusive approach, $\mathrm{ET}_{\mathrm{P}}$ must be estimated at a sub-diurnal frequency, as currently done in land surface models (LSMs). This study presents an improved method, developed in the

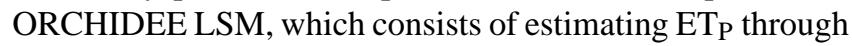
an unstressed surface-energy balance (USEB method). The results confirm the quality of the estimation which is currently implemented in the model (Milly, 1992). The $\mathrm{ET}_{\mathrm{P}}$ underlying the reference evaporation proposed by the Food and Agriculture Organization, FAO, (computed at a daily time step) has also been analysed and compared.

First, a comparison for a reference period under current climate conditions shows that USEB and FAO's ETP estimations differ, especially in arid areas. However, they produce similar values when the FAO's assumption of neutral stability conditions is relaxed, by replacing FAO's aerodynamic resistance by that of the model's. Furthermore, if the vapour pressure deficit (VPD) estimated for the FAO's equation, is substituted by ORCHIDEE's VPD or its humidity gradient, the agreement between the daily mean estimates of $\mathrm{ET}_{\mathrm{P}}$ is further improved.

In a second step, ETP's sensitivity to climate change is assessed by comparing trends in these formulations for the $21 \mathrm{st}$ century. It is found that the USEB method shows a higher
\end{abstract}

sensitivity than the FAO's. Both VPD and the model's humidity gradient, as well as the aerodynamic resistance have been identified as key parameters in governing $\mathrm{ET}_{\mathrm{P}}$ trends. Finally, the sensitivity study is extended to two empirical approximations based on net radiation and mass transfer (Priestley-Taylor and Rohwer, respectively). The sensitivity of these $\mathrm{ET}_{\mathrm{P}}$ estimates is compared to the one provided by USEB to test if simplified equations are able to reproduce the impact of climate change on $\mathrm{ET}_{\mathrm{P}}$.

\section{Introduction}

Potential evaporation $\left(\mathrm{ET}_{\mathrm{P}}\right)$ is a basic input for many hydrological and agronomic models that describes their interactions with the atmosphere. In addition, $\mathrm{ET}_{\mathrm{P}}$ is the basis of most actual evaporation estimations (Milly, 1992; Wang and Dickinson, 2012). Consequently, changes in $\mathrm{ET}_{\mathrm{P}}$ due to climate change will likely produce an effect on actual evaporation and more generally on the primary production of plants.

In 2007, the UNFCCC (United Nations Framework Convention on Climate Change) estimated the additional annual investment needed by 2030 to be able to bear the adaptation costs brought about by climate change. It was predicted to be up to 171 billion dollars at a global scale, out of which 8 and $6.5 \%$ correspond to the agricultural and water sectors, respectively (Parry et al., 2009). As ET $P$ determines agronomic and water resources estimates, the uncertainties in predicted trends for $\mathrm{ET}_{\mathrm{P}}$ should be taken into account. 
McMahon et al. (2013) explains that the term "potential evaporation" has been defined in several ways and provides examples of three different $\mathrm{ET}_{\mathrm{P}}$ definitions. In this study it is considered to be the amount of evaporation that would occur if enough water was available at the surface. As no land surface process limits the potential evaporation determined by available energy and aerodynamic resistance, this flux ends up being the atmospheric demand for water (Hobbins et al., 2008). Several methods have been developed to estimate its value. They can be grouped in two different families. One of them is dominated by the turbulent diffusion equation and mostly used in land surface models (LSMs). The other one is centred on a surface-energy balance equation (Monteith, 1981). The Penman-Monteith equation, which is recommended as the standard method to estimate $\mathrm{ET}_{\mathrm{P}}$ belongs to the second group. Even though both families treat the two equations (turbulent diffusion and surface-energy balance), each one estimates $\mathrm{ET}_{\mathrm{P}}$ putting more emphasis on one of them. This paper will refer to them as the diffusive and the surface-energy balance approaches. It must be remarked that $\mathrm{ET}_{\mathrm{P}}$ is a conceptual flux, since it can not be observed. Furthermore, as each method uses different hypotheses and approximations they can only provide an estimate of $\mathrm{ET}_{\mathrm{P}}$.

Concerning the first approach, Budyko's scheme (Budyko, 1956) uses a diffusive equation to estimate potential evaporation. It is obtained by taking the ratio of the humidity gradient and the aerodynamic resistance, multiplied by the air density. The gradient is the difference between the saturated humidity at the surface and the air's humidity. The virtual surface temperature, $T_{\mathrm{w}}$, which differs from the actual one in the fact that it is related to a hypothetically wet surface, is used to compute the saturated humidity. The most common way to implement this method in a general circulation model (GCM), however, is by using the actual surface temperature instead of the virtual one (Manabe, 1969). Since this leads to an overestimation of $\mathrm{ET}_{\mathrm{P}}$, Milly (1992) proposed a corrective term which takes into account the soil moisture stress's effect on the actual surface temperature. This paper presents a further step in the $\mathrm{ET}_{\mathrm{P}}$ computation by estimating virtual surface temperature through an unstressed surface-energy balance (USEB method). Thereby, the diffusive equation used to estimate $\mathrm{ET}_{\mathrm{P}}$ is closer to the original Budyko hypothesis and the Penman-Monteith method. It has been implemented in the ORCHIDEE (ORganising Carbon and Hydrology In Dynamic EcosystEms) LSM, developed by the Institut PierreSimon Laplace.

The second approach focuses on the energy partition between sensible and latent heat fluxes to obtain $\mathrm{ET}_{\mathrm{P}}$. An example is the Penman-Monteith equation, which is the basis for further simplifications, like the Food and Agricultural Organization (FAO) formulation that provides a reference evaporation (Allen et al., 1998). In this case, the assumed $\mathrm{ET}_{\mathrm{P}}$ (which can be computed setting the surface resistance to zero) is obtained using only standard meteorological data over a reference surface. This is an advantage for agronomic and hydrological models which do not have an explicit representation of the surface-energy balance and need an $\mathrm{ET}_{\mathrm{P}}$ estimation. Approximations have been derived for the FAO's equation for various time discretizations, from which the daily time step is retained for this study, as it is the most commonly used.

The lack of data availability, the desire to simplify the estimation of $\mathrm{ET}_{\mathrm{P}}$, or the need to perform local estimates have led to a number of approximations. Such is the case of radiation and mass-transfer-based methods. For example, the Priestley-Taylor equation approximates $\mathrm{ET}_{\mathrm{P}}$ through the net radiation (Xu and Singh, 2002). Another example is its estimation through pan evaporation (Campbell and Phene, 1976). In this case, the method of Kohler et al. (1955) is used. Simplifications have also been made for reference evaporation, like the Hargreaves method, which approximates it through the air temperature (Xu and Singh, 2002). It is also estimated by means of remote sensing (de Bruin et al., 2010), using geo-stationary satellite observations, daily downward solar flux at the surface, through a radiation-temperaturebased approximated formula given by Makkink (1957).

All of the aforementioned approximations have been adapted to provide comparable estimates of $\mathrm{ET}_{\mathrm{P}}$ for the current climate; however, it is known that variables used to determine $\mathrm{ET}_{\mathrm{P}}$ are affected by climate change. Kingston et al. (2009) analysed the climate change signal provided by six different $\mathrm{ET}_{\mathrm{P}}$ estimates. To perform this study, a scenario with a $2{ }^{\circ} \mathrm{C}$ rise in global mean temperature was used with five different global climate models. It was found that the simulated climate change signal differed between the methods used, and this was identified as an important factor in global freshwater availability projections. Therefore, the assumptions made in different methods when approximating $\mathrm{ET}_{\mathrm{P}}$ may not provide the correct sensitivity needed for a changing climate. This would result in a misleading estimation of $\mathrm{ET}_{\mathrm{P}}$ and eventually lead to poor projections which affect decisions regarding water resource management or crop yields.

The aim of this paper is to study the sensitivity of $\mathrm{ET}_{\mathrm{P}}$ to changes in atmospheric parameters which are expected to occur with climate change. To do so, $\mathrm{ET}_{\mathrm{P}}$ will be estimated using different methodologies. On the one hand, three LSM-based methods will be used. In this way, advantage will be taken of the LSM's sub-diurnal time step and the fact that it solves the energy balance and provides access to all atmospheric parameters needed. On the other hand, $\mathrm{ET}_{\mathrm{P}}$ will be computed using the FAO's reference equation and by means of two empirical approximations. These are a radiation-based (Priestley-Taylor) and a mass-transferbased (Rohwer) methods. Special attention will be paid to the aerodynamic resistance $\left(r_{\mathrm{a}}\right)$, as well as the vapour pressure deficit (VPD) and the humidity gradient, since they are approached in different ways in the methods and are found to be critical in the estimation of $\mathrm{ET}_{\mathrm{P}}$. 
Table 1. The different methodologies used in this study to compute $\mathrm{ET}_{\mathrm{P}}$.

\begin{tabular}{|c|c|c|}
\hline \multicolumn{3}{|c|}{ ET $_{\mathrm{P}}$ methodologies } \\
\hline Method & Equation & Comments \\
\hline Bulk & $\mathrm{ET}_{\mathrm{P} \text { Bulk }}=\frac{\rho}{r_{\mathrm{a}}}\left[q_{\mathrm{s}}\left(T_{\mathrm{s}}\right)-q_{\mathrm{a}}\right]$ & $\begin{array}{l}\text { Since } T_{\mathrm{S}} \text { is higher than } \\
T_{\mathrm{W}}, \mathrm{ET}_{\mathrm{P}} \text { is overestimated. }\end{array}$ \\
\hline Milly & $\mathrm{ET}_{\mathrm{P} \text { Milly }}=\frac{\rho}{r_{\mathrm{a}}}\left[q_{\mathrm{s}}\left(T_{\mathrm{S}}\right)-q_{\mathrm{a}}\right]\left(\frac{1}{1+\xi}\right)$ & $\begin{array}{l}T_{\mathrm{S}} \text { and } q_{\mathrm{s}}\left(T_{\mathrm{S}}\right) \text { are computed } \\
\text { through the normal surface } \\
\text { energy balance. Milly's correction } \\
\text { for soil moisture stress is applied. }\end{array}$ \\
\hline USEB & $\mathrm{ET}_{\mathrm{P} \text { USEB }}=\frac{\rho}{r_{\mathrm{a}}}\left[q_{\mathrm{s}}\left(T_{\mathrm{W}}\right)-q_{\mathrm{a}}\right]$ & $\begin{array}{l}T_{\mathrm{W}} \text { and } q_{\mathrm{s}}\left(T_{\mathrm{W}}\right) \text { are computed } \\
\text { through an unstressed surface } \\
\text { energy balance. }\end{array}$ \\
\hline $\begin{array}{l}\text { FAO } \\
\text { (saturated surface) }\end{array}$ & $\mathrm{ET}_{\mathrm{PFAO}}=\frac{\frac{1}{L} \Delta\left(R_{\mathrm{n}}-G\right)+\left[\frac{N_{\mathrm{d}} e}{R} C_{\mathrm{DFAO}} \frac{1}{\delta_{\mathrm{V}}}\right] \frac{\gamma}{T_{\mathrm{a}}+273} U_{2} \mathrm{VPD}}{\Delta+\gamma}$ & $\begin{array}{l}\text { The surface is considered } \\
\text { to be unstressed and no surface } \\
\text { resistance has been considered. }\end{array}$ \\
\hline Priestley-Taylor & $\mathrm{ET}_{\mathrm{P} \mathrm{PT}}=\alpha \frac{\Delta}{(\Delta+\gamma)} \frac{R_{\mathrm{n}}}{L}$ & Radiation-based method \\
\hline Rohwer & $\mathrm{ET}_{\mathrm{P} \mathrm{ROH}}=0.44\left(1+0.27 U_{2}\right) \mathrm{VPD}$ & Mass-transfer-based method \\
\hline
\end{tabular}

Table 2. Description of $\mathrm{ET}_{\mathrm{P}} \mathrm{USEB}_{\mathrm{B}}, \mathrm{ET}_{\mathrm{P} B U \mathrm{~B}}, \mathrm{ET}_{\mathrm{P} \text { Milly }}$ and the cases defined to compute $\mathrm{ET}_{\mathrm{P} F A O}$, according to the variables they depend on and the assumptions made for their calculation. The computation has been carried out at a daily time step, except for the following cases: a The time step computation of $\mathrm{ET}_{\mathrm{P}}$ has been the LSM's one, $30 \mathrm{~min}$. A daily mean has been computed afterwards.

$\mathrm{b}$ The parameter's time step computation has been the LSM's one, $30 \mathrm{~min}$. Next a daily mean has been saved to use it in FAO's equation.

\begin{tabular}{|c|c|c|c|}
\hline \multicolumn{4}{|c|}{$\mathrm{ET}_{\mathrm{P}}$ methodologies and assumptions } \\
\hline Method & Temperature & Deficit/Gradient & Aerodynamic Resistance \\
\hline${ }^{\text {a }}$ USEB & $T_{\mathrm{W}}$ & $q_{\mathrm{s}}\left(T_{\mathrm{W}}\right)-q_{\mathrm{a}}$ & $r_{\mathrm{a} \text { ORC }}=\left(C_{\mathrm{D} \mathrm{ORC}} U_{2}\right)^{-1}$ \\
\hline${ }^{a}$ Bulk and Milly & $T_{\mathrm{S}}$ & $q_{\mathrm{s}}\left(T_{\mathrm{s}}\right)-q_{\mathrm{a}}$ & As USEB \\
\hline FAO case 1 & $\frac{T_{\mathrm{a} \max }+T_{\mathrm{a} \min }}{2}$ & FAO's proposal & FAO's proposal \\
\hline FAO case 2 & As FAO Case 1 & $\begin{array}{l}\mathrm{VPD}=P_{\mathrm{S}}\left(T_{\mathrm{a}}\right)-P_{\mathrm{a}} \\
\text { ORCHIDEE's computation } \\
\text { Gradient }=P_{\mathrm{S}}\left(T_{\mathrm{S}}\right)-P_{\mathrm{a}}\end{array}$ & $\begin{array}{l}r_{\mathrm{a} F A O}=\left(C_{\mathrm{D} \mathrm{FAO}} U_{2}\right)^{-1} \\
\text { As FAO Case } 1\end{array}$ \\
\hline FAO case 3 & As FAO Case 1 & As FAO Case 1 & As USEB \\
\hline FAO case 4 & As FAO Case 1 & As FAO Case 2 & As USEB \\
\hline FAO case 5 & As FAO Case 1 & $\begin{array}{l}{ }^{\mathrm{b}} \text { ORCHIDEE's computation } \\
\mathrm{VPD}_{\mathrm{ORC}}=P_{\mathrm{S}}\left(T_{\mathrm{a}}\right)-P_{\mathrm{a}}\end{array}$ & As FAO Case 1 \\
\hline FAO case 6 & As FAO Case 1 & As FAO Case 5 & As USEB \\
\hline
\end{tabular}

ETP's estimation and the USEB method's implementation in ORCHIDEE are described, as well as FAO's reference equation. The two empirical approximations are also explained. A result section will follow, showing a comparison between the LSM and FAO methodologies and how under the current climate, the difference between them is reduced when the atmosphere's stability is taken into account in the FAO equation. Afterwards, the impact of climate change on $\mathrm{ET}_{\mathrm{P}}$ will be studied. In addition, variables used for estimating $\mathrm{ET}_{\mathrm{P}}$ will also be analysed in order to identify the key parameters which are sensitive to the expected changes. Finally the paper will conclude with a recommendation for estimating $\mathrm{ET}_{\mathrm{P}}$ in a changing climate.

\section{Methodology}

The different methodologies used to estimate $\mathrm{ET}_{\mathrm{P}}$ in this study will be explained and summarised in Table 1. Next, the forcing data used will be presented. Lastly, a comparison will be made between the VPDs, humidity gradients, and $r_{\mathrm{a}}$ definitions from FAO and ORCHIDEE. This will lead to the 
definition of six different options to compute ETp using the FAO equation, which will be detailed in Table 2 .

\subsection{Definition of potential evaporation in ORCHIDEE: bulk, Milly and USEB methods}

Before this study was initiated and the USEB method implemented in ORCHIDEE, there were already two methods for computing potential evaporation implemented in the LSM: the bulk method and Milly's method (de Rosnay et al., 2002).

\subsubsection{Bulk method}

Potential evaporation is computed following Manabe's scheme, (Manabe, 1969). It is based on Budyko's approach, where ETP is the product between the air density $\rho$ and the humidity gradient, divided by the aerodynamic resistance $r_{\mathrm{a}}$. By definition, the gradient's saturated humidity should be computed using a virtual temperature, $T_{\mathrm{w}}$. However, the way in which this method is usually implemented in LSMs is to use the actual surface temperature, $T_{\mathrm{s}}$ :

$\operatorname{ET}_{\mathrm{P}}\left(T_{\mathrm{s}}\right)=\frac{\rho}{r_{\mathrm{a}}}\left[q_{\mathrm{s}}\left(T_{\mathrm{s}}\right)-q_{\mathrm{a}}\right]$,

where $q_{\mathrm{s}}$ is the specific humidity of saturated air and $q_{\mathrm{a}}$ is the specific air humidity. The actual surface temperature confirms the following simplified energy balance equation:

$R_{\mathrm{n}}-G=\beta_{\mathrm{s}} \frac{L \rho}{r_{\mathrm{a}}}\left[q_{\mathrm{s}}\left(T_{\mathrm{s}}\right)-q_{\mathrm{a}}\right]+\frac{\rho c_{\mathrm{p}}}{r_{\mathrm{a}}}\left[T_{\mathrm{s}}-T_{\mathrm{a}}\right]$,

$R_{\mathrm{n}}$ being the net radiation and $G$ being the soil heat flux. $T_{\mathrm{a}}$ is the air temperature, $L$ is the latent heat of vaporization of water and the specific heat of the air is denoted by $c_{\mathrm{p}}$. $\beta_{\mathrm{s}}$ is a parameter named the "moisture availability function", which reduces $\mathrm{ET}_{\mathrm{P}}$ to actual evaporation (ET) when water supply is limited:

$\mathrm{ET}=\beta_{\mathrm{s}} \mathrm{ET}_{\mathrm{P}}\left(T_{\mathrm{S}}\right)$

From now on the ETP computed by means of Eq. (1) will be referred to as $\mathrm{ET}_{\mathrm{P} \text { BULK }}$.

Models computing potential evaporation as indicated in Eq. (1) will overestimate it, since $T_{\mathrm{S}}$ is greater or equal (if the surface is unstressed) to $T_{\mathrm{w}}$. As the surface gets drier, the difference between $T_{\mathrm{w}}$ and $T_{\mathrm{s}}$ will increase, amplifying the overestimation of $\mathrm{ET}_{\mathrm{P}}$. In order to obtain a better estimate, the humidity gradient must be reduced. There are two ways to do this: The first is to develop a correcting factor for the bulk formula (Milly, 1992), and the second is to compute a virtual temperature and use that to calculate the humidity gradient (USEB method).

Since it has been proven that the bulk method overestimates $\mathrm{ET}_{\mathrm{P}}$ (Milly, 1992), this method's estimation will not be analysed in this paper. Its response to climate change will nevertheless be analysed and compared to the responses of the other methodologies.

\subsubsection{Milly's method}

In order to reconcile the estimation of $\mathrm{ET}_{\mathrm{P}}$ using $T_{\mathrm{S}}$ instead of $T_{\mathrm{w}}$, Milly proposed to apply a correction to the bulk formula in 1992 . He did so by computing the relative error $(\xi)$ given by the use of the actual surface temperature:

$\xi=\frac{\operatorname{ET}_{\mathrm{P}}\left(T_{\mathrm{s}}\right)-\mathrm{ET}_{\mathrm{P}}\left(T_{\mathrm{w}}\right)}{\operatorname{ET}_{\mathrm{P}}\left(T_{\mathrm{w}}\right)}=\frac{\frac{L \rho}{r_{\mathrm{a}}} q_{\mathrm{s}}^{\prime}\left(T_{\mathrm{a}}\right)\left[1-\beta_{\mathrm{s}}\right]}{4 \varepsilon \sigma T_{\mathrm{a}}^{3}+\frac{\rho c_{\mathrm{p}}}{r_{\mathrm{a}}}+\frac{L \rho}{r_{\mathrm{a}}} q_{\mathrm{S}}^{\prime}\left(T_{\mathrm{a}}\right) \beta_{\mathrm{s}}}$,

where $\varepsilon$ is the emissivity, $\sigma$ the Stefan-Boltzmann constant, and $q_{\mathrm{s}}^{\prime}$ the derivative of $q_{\mathrm{s}}$ with respect to temperature, evaluated at $T_{\mathrm{a}}$. From now on, the ETP computed by means of Eq. (1) with the application of Milly's correction (see Table 1) will be referred to as ETPMILLY.

\subsubsection{USEB method}

The aim of the USEB (Unstressed Surface-Energy Balance) method is to estimate $\mathrm{ET}_{\mathrm{P}}$ in a LSM considering a non-stressed surface. This is a new means of computing $\mathrm{ET}_{\mathrm{P}}$ which has been developed in the ORCHIDEE LSM. Like the other two methods, it has been implemented in the SECHIBA module, Schématisation des EChanges Hydriques à l'Interface Biosphère-Atmosphère (de Rosnay and Polcher, 1998), which simulates physical processes between the ground, the vegetation and the atmosphere, as well as the ground's hydrological cycle. The LSM can be run coupled with the general circulation model LMDZ, which was developed by the Laboratoire de Météorologie Dynamique (LMD), or on a stand-alone mode. For this study, uncoupled simulations have been carried out. The computation time step is typically $30 \mathrm{~min}$, allowing for a full representation of the diurnal cycle.

The first step is to compute a new energy balance in ORCHIDEE, differing from the existing one by the fact that the surface is considered to be saturated, as proposed by Milly (1992). This is achieved by neglecting the surface resistance in the energy balance calculation. The soil heat flux is the one used in the normal energy balance. The effect of $G$ on the unstressed surface-energy balance has been assumed to be negligible. Next, the virtual temperature is used to calculate the saturated humidity. Finally, ETP is obtained following Budyko (1956). The relation used is Eq. (1), but the virtual temperature, $T_{\mathrm{w}}$, is used instead of $T_{\mathrm{S}}$ (see Table 1). From now on the $\mathrm{ET}_{\mathrm{P}}$ computed using the USEB method will be referred to as ETP USEB .

Actual evaporation may be computed through an unstressed surface-energy balance. In order to do this, it is computed using Eq. (3), but $\operatorname{ET}_{\mathrm{P}}\left(T_{\mathrm{w}}\right)$ and $\beta_{\mathrm{w}}$ have to be used instead of $\operatorname{ET}_{\mathrm{P}}\left(T_{\mathrm{s}}\right)$ and $\beta_{\mathrm{s}} . \beta_{\mathrm{w}}$ and $\beta_{\mathrm{s}}$ are not likely to be equal, because the different assumptions about the temperature used in $\mathrm{ET}_{\mathrm{P}}$ will lead to a very different atmospheric demand. Therefore, it is very likely that the different assumptions made in LSMs regarding $\mathrm{ET}_{\mathrm{P}}$ will lead to a different 
adaptation of the parameters used in the formulation of the moisture availability function.

\subsection{FAO reference evapotranspiration equation}

The Food and Agriculture Organization Irrigation and Drainage Paper no. 56 provides a methodology to estimate a daily mean reference evaporation $\left(\mathrm{ET}_{\mathrm{o}}\right)$ on a reference surface, using meteorological data from a height of $2 \mathrm{~m}$. This reference surface is defined as a "hypothetical reference crop with an assumed crop height of $0.12 \mathrm{~m}$, a fixed surface resistance of $70 \mathrm{sm}^{-1}$ and an albedo of $0.23 "$. It is described as an extensive surface of green grass of equal height, actively growing, not short of water and where the ground can not be seen. The ETP assumed in the FAO formulation can be obtained for the reference surface by setting the surface resistance to zero. This $\mathrm{ET}_{\mathrm{P}}$ will be the variable analysed in this study. While various time averages are provided by the FAO, we limit ourselves to the daily mean estimate as it is the most widely used.

The Penman-Monteith combination method, which combines the surface-energy balance and diffusive approaches, is adopted as the standard for reference evaporation:

$\mathrm{LET}=\frac{\Delta\left(R_{\mathrm{n}}-G\right)+\rho c_{\mathrm{p}} \frac{\mathrm{VPD}}{r_{\mathrm{a}}}}{\Delta+\gamma\left(1+\frac{r_{\mathrm{s}}}{r_{\mathrm{a}}}\right)}$,

where $\Delta$ is the slope of the vapour pressure curve, $\gamma$ the psychrometric constant and $r_{\mathrm{s}}$ the surface resistance. The VPD represents the vapour pressure deficit of the air. It is the difference between the saturation vapour pressure $P_{\mathrm{s}}\left(T_{\mathrm{a}}\right)$ and the actual vapour pressure $P_{\mathrm{a}}$. In order to obtain the FAO's reference equation, the $\rho$ and the $c_{\mathrm{p}}$ are replaced by the following expressions:

$c_{\mathrm{p}}=\frac{\gamma e L}{P}$

and

$\rho=\frac{P}{\delta_{\mathrm{v}}\left(T_{\mathrm{a}}+273\right) R}$,

where $\delta_{\mathrm{v}}=1.01$ is used to approximate the virtual temperature throughout $T_{\mathrm{a}} . R$ is the specific gas constant $\left(\mathrm{kJ} \mathrm{kg}^{-1} \mathrm{~K}^{-1}\right)$, $e$ the ratio of molecular weight of water vapour/dry air and $P$ the atmospheric pressure.

Neutral stability conditions, together with the fact that a fixed reference surface is taken into account, allow the approximation of the surface resistance to $70 \mathrm{~s} \mathrm{~m}^{-1}$ and the aerodynamic resistance to

$r_{\mathrm{a} F \mathrm{FAO}}=\left(C_{\mathrm{DFAO}} U_{2}\right)^{-1}$,

where $C_{\mathrm{DFAO}}=208^{-1}$ is referred to in this paper as FAO's drag coefficient and $U_{2}$ is the wind speed.
Finally, if these approximations are substituted into Eq. (5) together with Eq. (6) to Eq. (8), the $\mathrm{ET}_{\mathrm{o}}$ given in $\mathrm{mmd}^{-1}$ is

$\mathrm{ET}_{\mathrm{o}}=\frac{\frac{1}{L} \Delta\left(R_{\mathrm{n}}-G\right)+\left[\frac{N_{\mathrm{d}} e}{R} C_{\mathrm{D} \mathrm{FAO}} \frac{1}{\delta_{\mathrm{v}}}\right] \frac{\gamma}{T_{\mathrm{a}}+273} U_{2} \mathrm{VPD}}{\Delta+\gamma\left(1+\left[r_{\mathrm{S}} C_{\mathrm{D} \mathrm{FAO}}\right] U_{2}\right)}$,

where $N_{\mathrm{d}}$ is the number of seconds per day. The numerator's term in square brackets is approximated to 900 and the denominator's to 0.34 . As it has been explained in the previous section, no surface resistance has been considered in the USEB method implementation. Our aim is to estimate the $\mathrm{ET}_{\mathrm{P}}$ underlying the $\mathrm{FAO}$ equation. Therefore, according to the definition of $\mathrm{ET}_{\mathrm{P}}$ provided, $r_{\mathrm{s}}=0$ in FAO's equation. From now on the $\mathrm{ET}_{\mathrm{P}}$ computed using FAO's method, will be referred to as $\mathrm{ET}_{\mathrm{P} F A O}$.

To estimate $\mathrm{ET}_{\mathrm{P}}$ by means of FAO's reference equation, the daily mean forcing variables which are required are the wind speed $\left(\mathrm{m} \mathrm{s}^{-1}\right)$, for the $r_{\mathrm{a}}$, and the net short-wave and long-wave radiation $\left(\mathrm{MJ} \mathrm{m}^{-2} \mathrm{~d}^{-1}\right)$, to compute $R_{\mathrm{n}}$ and $G$. Moreover, the maximums and minimums of both the relative humidity $(\%)$ and the temperature $\left({ }^{\circ} \mathrm{C}\right)$ are also needed to obtain the daily average of VPD and $\Delta$, which is a function of temperature. Section 2.4 details how they have been obtained.

\subsection{Radiation and mass-transfer-based methods}

Two different formulations have been used in this study to compute empirical estimates of the atmospheric demand: Priestley-Taylor (radiation-based-method) and Rohwer (mass-transfer-based method), both detailed in Xu and Singh (2002). These methods were selected because there was more data available about them and because methods were desired for which the atmospheric demand was approximated through different variables. The equations are presented in Table 1.

Priestley and Taylor (1972) simplify the combination equation (Penman, 1948), basing the ETP estimation on the net radiation. Apart from the $R_{\mathrm{n}}$, the $\Delta$ and $\gamma$ from FAO's equation and a coefficient $\alpha=1.26$ are also used.

Rohwer's method (Rohwer, 1931) is a version of the Dalton equation and approximates ETP through the VPD and $U_{2}$. The VPD has been computed as it is proposed in FAO's reference equation.

Since these formulations include site specific parameters which need to be calibrated for each location, their representation of the atmospheric demand over the globe for the current climate will not be examined in this paper. Nevertheless, their sensitivity to the impact of climate change on the atmospheric forcing can be considered to a first order as independent of the site specific parameters. Therefore, this paper will examine the general global shape of the response of these empirical formulations, assuming that they will be mostly independent of site specific adaptation, which would have to be undertaken before they could be applied to impact models. 


\subsection{Forcing data}

The study has been carried out for two different periods: a reference period (from 1990 to 2000) and a future scenario period (from 2000 to 2100). The ORCHIDEE simulation for the reference period permits a comparison between the model and FAO's output. The future scenario simulation is performed in order to examine the sensitivity of the $\mathrm{ET}_{\mathrm{P}}$ estimations to climate change.

The Water and Global Change (WATCH, www.eu-watch. org) Forcing Data (WFD) used for the reference period simulation consists of sub-daily, regularly gridded meteorological forcing data, obtained using a bias correction of the ECMWF re-analysis. It has a resolution of half a degree, and extends from 1958 to 2001 (Weedon et al., 2011). Regarding the future period, the forcing data employed is the bias corrected IPSL A2 scenario (Piani et al., 2010) which includes data from the year 2000 until 2100. It is considered to be a greenhouse gas increase scenario, based on the IPCC fourth Special Report on Emissions Scenarios.

FAO and the empirical approximations' estimates will use daily averages of WFD/IPSL A2 scenario except for variables which are affected by land surface properties. For these variables, daily averages diagnosed within ORCHIDEE are used. Therefore, atmospheric variables, namely, the wind speed and the maximums and minimums of both the relative humidity and the air temperature, correspond to those given by the WFD/IPSL A2 scenario. On the other hand, surface related parameters, like the net radiation, contain information from both the WFD/IPSL A2 scenario and ORCHIDEE. In addition to producing direct estimates of $\mathrm{ET}_{\mathrm{P}}$, detailed in Sect. 2.1, the simulations for the reference period and the future scenario period also provided the variables affected by land surface properties. These were needed to compute ET using the FAO equation and the empirical approximations described in the previous section. As a result, the climate conditions are equal for all estimations of $\mathrm{ET}_{\mathrm{P}}$.

\subsection{Comparison of methodologies}

FAO's approximation of the $r_{\mathrm{a}}$ and VPD differs from their computation in ORCHIDEE. So, apart from the original $\mathrm{ET}_{\mathrm{P}}$ estimation proposed by the $\mathrm{FAO}$, five alternative estimations were performed replacing the original $r_{\mathrm{a}}$ by ORCHIDEE's and its VPD by the VPD computed in ORCHIDEE and the model's humidity gradient. These as well as ORCHIDEE's estimations are explained in Table 2.

\subsubsection{Aerodynamic resistance}

When a reference surface is chosen for the computation of $\mathrm{ET}_{\mathrm{P}}$, the area of validity is limited. For instance, the Environmental and Water Resources Institute (EWRI) provides a standardized reference evapotranspiration equation, which distinguishes between tall and short crops regarding the ref- erence surface (Walter et al., 2005). Therefore, the aerodynamic resistance differs between the two types of crops. Since $r_{\mathrm{a}}$ will be lower for tall crops than for short ones, $\mathrm{ET}_{\mathrm{P}}$ will increase for the former.

FAO's $r_{\mathrm{a}}$ assumes neutral stability conditions and a reference surface with specific characteristics. This results in a constant drag coefficient $\left(C_{\mathrm{DFAO}}\right)$ and the wind speed being the only time evolving variable in the calculation of $r_{\mathrm{a}}$. On the contrary, the drag coefficient in ORCHIDEE's computation $\left(C_{D}\right.$ ORC $)$ varies as a function of the surface roughness and atmospheric stability following the Louis scheme (Louis, 1979). This $r_{\mathrm{a}}$ is used in the bulk formula, the USEB, and Milly's method, and is obtained according to

$r_{\mathrm{a} \text { ORC }}=\left(C_{\mathrm{D} \mathrm{ORC}} U_{2}\right)^{-1}$.

Unlike FAO's treatment, ORCHIDEE is not limited to a unique reference surface, meaning that roughness is variable in space and time. It provides a representation of the vegetation variability considering 13 different PFT (Plant Functional Type), detailed in Krinner et al. (2005). So if ORCHIDEE's $r_{\mathrm{a}}$ replaces that of the FAO, we will not only take into account the different surface types, but the time evolving atmospheric stability as well.

To replace FAO's $r_{\mathrm{a}}$ with ORCHIDEE's $r_{\mathrm{a}}$, the drag coefficient computed in the LSM $\left(C_{\mathrm{D} \text { ORC }}\right)$ has been saved for usage in FAO's equation. For the cases where the $r_{\mathrm{a}}$ is replaced, ETP FAO will be computed as follows:

$\mathrm{ET}_{\mathrm{PFAO}}=\frac{\frac{1}{L} \Delta\left(R_{\mathrm{n}}-G\right)+\left[\frac{N_{\mathrm{d}} e}{R} C_{\mathrm{D} \mathrm{FAO}} \frac{1}{\delta_{\mathrm{v}}}\right] \frac{\gamma}{T_{\mathrm{a}}+273} U_{2} \frac{C_{\mathrm{D} O R C}}{C_{\mathrm{DFAO}} \mathrm{VPD}}}{\Delta+\gamma}$.

\subsubsection{VPD and humidity gradient}

Allen et al. (1998) states that the difference between the water vapour pressure from the evaporating surface and the surrounding atmosphere is the driving force that removes water vapour from the surface. This process is approached in a different way depending on the methodology used to calculate $\mathrm{ET}_{\mathrm{P}}$. For example, estimations based on observations will only use a VPD, because $T_{\mathrm{w}}$ can not be measured. The Penman-Monteith combination method, which is the basis of FAO's equation, computes a VPD. However, ETP estimates in models generally use the gradient, as surface information is available. In the first case, the calculation is limited to the air at $2 \mathrm{~m}$, while in the second one both the air and the surface are considered.

FAO's equation proposes several approximations of the VPD, and the user chooses between them based on the availability of atmospheric data. For this study the approximation detailed in Allen et al. (1998), which uses the maximum and minimum $2 \mathrm{~m}$ temperatures and relative humidities, $\mathrm{RH}$, has been employed. In order to compute it, daily averages of these variables have been obtained from the WFD/IPSL A2 scenario data sets. 
Table 3. Mean $\mathrm{ET}_{\mathrm{P}}$ for the reference period regarding the USEB and Milly methods, as well as the FAO's six cases.

\begin{tabular}{|c|c|c|c|c|c|}
\hline \multicolumn{6}{|c|}{$\mathrm{ET}_{\mathrm{P}}\left(\mathrm{mmd}^{-1}\right)$ for the reference period } \\
\hline \multicolumn{2}{|c|}{ Method } & \multirow{2}{*}{$\begin{array}{r}\text { Australia } \\
14.5\end{array}$} & \multirow{2}{*}{$\begin{array}{c}\text { Sahel } \\
9.5\end{array}$} & \multirow{2}{*}{$\begin{array}{c}\text { Central Europe } \\
2.1\end{array}$} & \multirow{2}{*}{$\frac{\text { Amazon Basin }}{3.8}$} \\
\hline ORCHIDEE & USEB & & & & \\
\hline & Milly & 13.8 & 9.5 & 2.2 & 4 \\
\hline \multirow[t]{6}{*}{ FAO } & Case 1 & 5.8 & 5.4 & 1.6 & 2.5 \\
\hline & Case 2 & 5.7 & 4.9 & 1.2 & 2.4 \\
\hline & Case 3 & 14.2 & 9.3 & 2.5 & 4.2 \\
\hline & Case 4 & 13.5 & 7.9 & 1.8 & 3.5 \\
\hline & Case 5 & 5.6 & 5.2 & 1.5 & 2.4 \\
\hline & Case 6 & 13.3 & 8.9 & 2.3 & 3.6 \\
\hline
\end{tabular}

On the other hand, $\mathrm{ET}_{\mathrm{P} \text { BULK }}, \mathrm{ET}_{\mathrm{P}}$ USEB and $\mathrm{ET}_{\mathrm{P} \text { Milly }}$ are computed using a specific humidity gradient. Taking advantage of ORCHIDEE, the LSM uses the Clausius-Clapeyron equation with a 30 min time step, resulting in a precise representation of the diurnal cycle. Two different gradients are computed in ORCHIDEE: the first is used in the bulk formula and Milly's method, where $q_{\mathrm{s}}$ is computed with $T_{\mathrm{s}}$. The second is used for the USEB method implementation, and $q_{\mathrm{s}}$ is computed by means of the virtual temperature, $T_{\mathrm{w}}$.

In order to test the differences between the two representations of the water vapour removal, $\mathrm{ET}_{\mathrm{P} F \mathrm{FO}}$ has been computed, replacing its VPD by ORCHIDEE's humidity gradient, converted to a vapour pressure gradient. Since the FAO's equation considers an actual temperature instead of a virtual one, the LSM's gradient from the bulk formula, which is calculated using $T_{\mathrm{s}}$, is more appropriate for use in FAO's formulation. To compute this gradient, ORCHIDEE's daily estimates of the humidity of the air and the saturated surface have been used. Separately, the difference between the saturated vapour pressure and the air vapour pressure at $2 \mathrm{~m}$ $\left(\mathrm{VPD}_{\mathrm{ORC}}\right)$ was also saved from the WFD/IPSL A2 scenario, in order to calculate $\mathrm{ET}_{\mathrm{P}} \mathrm{FAO}$. This will allow the comparison with the $\mathrm{ET}_{\mathrm{PFAO}}$ results obtained using the humidity gradient and test the quality of FAO's estimation of the daily mean VPD.

Daily potential evaporation was computed for the different methodologies and cases. Afterwards, the monthly and yearly means were calculated. Negative monthly ET $_{P}$ occurring under inconsistent atmospheric forcings were set to zero in the averaging processes.

In order to approach the climate change sensitivity study, trends for the different $\mathrm{ET} \mathrm{P}_{\mathrm{P}}$ methods, as well as the VPD, gradients, $r_{\mathrm{a}}$, and $R_{\mathrm{n}}$ have been computed. The significance level chosen in this analysis is $95 \%$ (computed using the CoxStuart test).

\section{Results and discussion}

The various estimations of $\mathrm{ET}_{\mathrm{P}}$ will be compared in this section. To begin with, the reference period will be assessed, showing ORCHIDEE's computation (using USEB and Milly's methods) as well as FAO's equation results computed as explained in Tables 1 and 2. Afterwards, $\mathrm{ET}_{\mathrm{P}}$ trends for ORCHIDEE's computations, FAO's reference equation (considering the six cases) and the two simplified approximations will be analysed with respect to the effects of climate change.

We would like to point out that as $\mathrm{ET}_{\mathrm{P}}$ is a conceptual flux, we will always deal with estimates. Therefore different LSM's estimates may differ from each other. In our study the different methodologies' estimates and trends have been compared with those from the USEB method. In our opinion, this methodology contains most of the physical processes which are important for $\mathrm{ET}_{\mathrm{P}}$ estimation and its sensitivity to climate change. The atmospheric stability, which has been shown to be considered by ORCHIDEE's aerodynamic resistance computation, but not by FAO's, is one example.

In order to facilitate the comparison, four regions have been selected for analysis using the different methodologies, with the aim of sampling different climates, surface characteristics, and vegetation types. Two dry areas were chosen, situated in northern Australia $\left(110^{\circ} \mathrm{E}-140^{\circ} \mathrm{E}, 10^{\circ} \mathrm{S}-30^{\circ} \mathrm{S}\right)$ and in the Sahel $\left(20^{\circ} \mathrm{W}-15^{\circ} \mathrm{E}, 10^{\circ} \mathrm{N}-20^{\circ} \mathrm{N}\right)$, representing semi-arid and arid regions. Two humid areas were chosen, one in a temperate region, Central Europe $\left(0-14^{\circ} \mathrm{E}, 44^{\circ} \mathrm{N}-\right.$ $54^{\circ} \mathrm{N}$ ), and one in a tropical region, the Amazon Basin $\left(70^{\circ} \mathrm{W}-50^{\circ} \mathrm{W}, 2^{\circ} \mathrm{N}-14^{\circ} \mathrm{S}\right)$.

\subsection{Comparison of ET $_{P}$ estimates}

Table 3 shows mean annual $\mathrm{ET}_{\mathrm{P}}$ values for the selected regions computed using the USEB and Milly methods, as well as the six cases defined for the FAO's equation. This comparison between methodologies is also analysed at a global scale in Fig. 1. It must be stressed that the results from Table 3 are general across the globe, as can be observed 

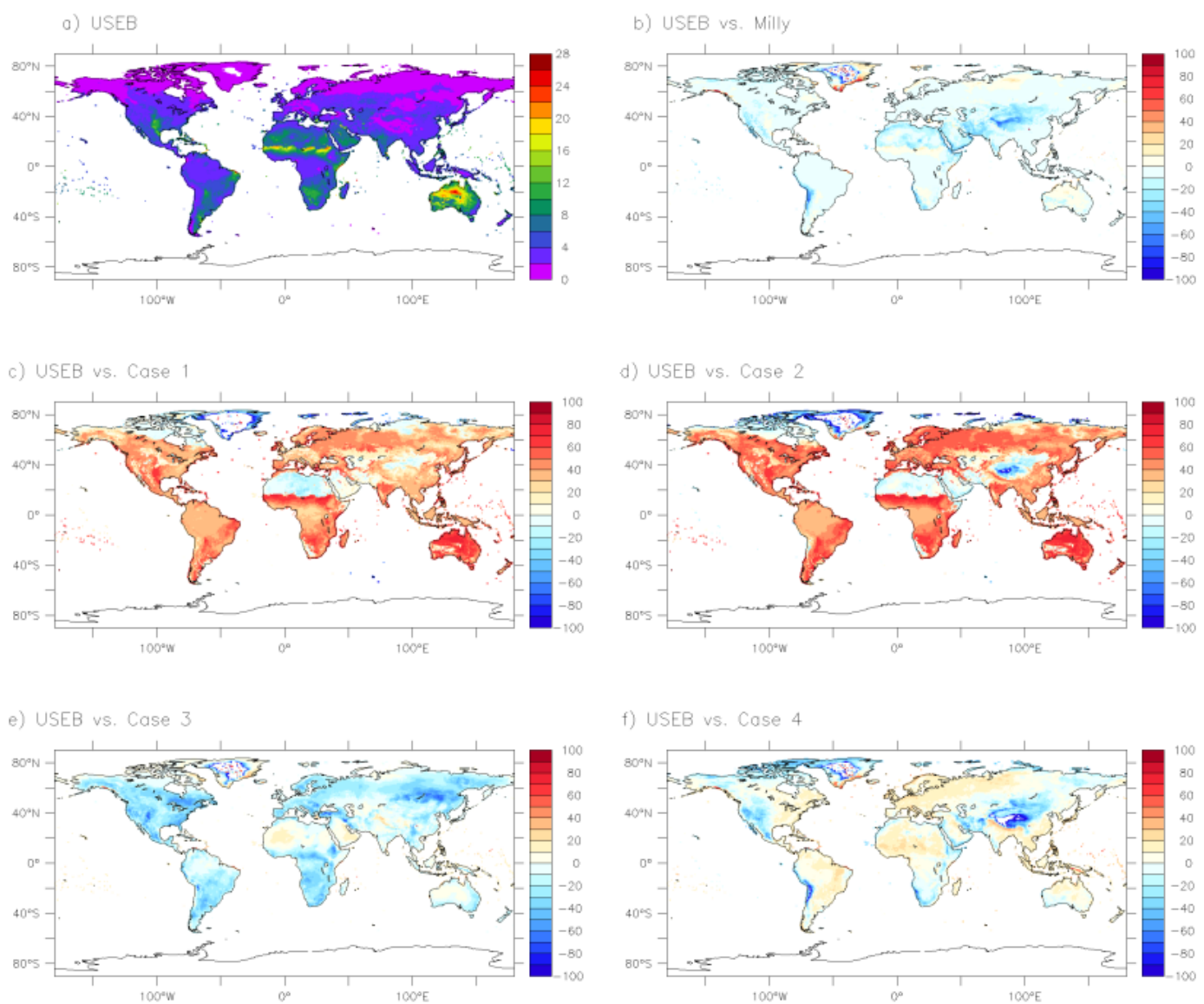

Fig. 1. The USEB method's ETP mean annual values $\left(\mathrm{mm} \mathrm{d}^{-1}\right)$ for the reference period (a). Differences, given in $\%$, between the USEB and Milly methods (b), as well as between the USEB method and the first four cases defined for FAO's equation (c to $\mathbf{f}$ ). Whereas red colours provide higher values dealing the USEB method, blue ones imply that FAO's reference equation or Milly's method provide higher ET ${ }_{P}$ values.

in Fig. 1. This figure shows mean annual $\mathrm{ET}_{\mathrm{P}}$ values for the USEB method (Fig. 1a), its percentage difference with Milly's method (Fig. 1b), and FAO's ETP estimation (Fig. 1c to f). Cases 5 and 6 for FAO's computation have not been included, due to their similarity with cases 2 and 4 .

First, the USEB and Milly methods provide equivalent results in humid and arid regions. This result shows that using the actual surface temperature overestimates $\mathrm{ET}_{\mathrm{P}}$, and that both methodologies succeed in estimating a more accurate value (Milly, 1992).

Second, values estimated by the FAO's equation (case 1) are lower than those provided by the USEB method, specially in arid areas, as shown in Fig. 1c. For example, in the Australian region, the FAO's ETP is $60 \%$ lower than that of USEB, whereas in the Central European region it is $24 \%$ lower. Smaller differences are expected between the estimations in humid regions, since FAO's equation was designed for continuously wet areas. In order to explain the differences between these two methodologies, the cases defined for FAO's equation, and thus the role of the approxi- mations made for the VPD and $r_{\mathrm{a}}$, have been analysed. The differences between cases 1,2 and 5 will provide information about the effect of FAO's VPD approximation compared

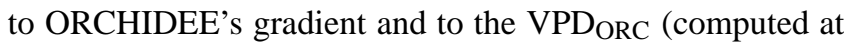
a higher frequency). Case 1 compared to case 3 will serve to test the impact of the aerodynamic resistance effect when the assumption of neutral stability conditions defined in FAO's estimation is lifted. Finally, cases 4 and 6 will show the combined effect of the LSM's gradient/VPD $\mathrm{ORC}$ with its $r_{\mathrm{a}}$.

Table 3 and Fig. 1e identify case 3 as the one that shows the largest increase of $\mathrm{ET}_{\mathrm{P}}$ in FAO's equation. According to its definition (see Table 1), ETP increases if the $r_{\mathrm{a}}$ decreases. Taking into account the fact that higher $\mathrm{ET}_{\mathrm{P}}$ values are yielded when ORCHIDEE's $r_{\mathrm{a}}$ is used in FAO's equation (cases 3, 4 and 6), we conclude that the assumption of a neutral atmosphere and the neglect of surface roughness in the FAO's formulation leads to the overestimation of $r_{\mathrm{a}}$. Comparing case 1 to cases 3,4 and 6 , it can be concluded that the assumption about the surface layer turbulence plays an important role. If it is relaxed by using the LSM's $r_{\mathrm{a}}$, the 
difference from the USEB method is strongly reduced, as shown in Fig. 1e and $\mathrm{f}$.

The gradient obtained from the bulk formula and the $\mathrm{VPD}_{\mathrm{ORC}}$ are smaller than FAO's VPD, leading to higher $\mathrm{ET}_{\mathrm{P}}$ estimates of FAO's case 1 compared to cases 2 and 5. As expected, VPD ${ }_{\mathrm{ORC}}$ and FAO's VPD are very close to each other, but the humidity gradient differs slightly more. The FAO's way of calculating VPD is expected to overestimate $\mathrm{ET}_{\mathrm{P}}$ in non-reference (arid) areas because there is a higher $T_{\mathrm{a}}$ and a lower $P_{\mathrm{a}}$ in these areas, which would yield a higher VPD than that which would occur under reference conditions (Allen et al., 1998). As a result, FAO's VPD approximation using the maximum and minimum $2 \mathrm{~m}$ temperatures and relative humidities overestimates the atmospheric demand. On the other hand, deriving VPD $\mathrm{ORC}_{\mathrm{O}}$ or using ORCHIDEE's humidity gradient implies a sub-diurnal frequency computation, the availability of all the variables needed, and a better representation of the diurnal cycle. For this reason, we recommend the use of a LSM to compute the VPD instead of the approximation of the FAO. Apart from VPD ${ }_{\text {ORC }}$, FAO's equation has also been computed with the bulk formula's gradient and the results match each other. If Fig. 1c and d are compared, the effect of using FAO's approximation or the humidity gradient from the bulk formula can be observed.

Figure 1f shows that the combined effect of ORCHIDEE's $r_{\mathrm{a}}$ with the bulk formula's gradient (case 4) provides an $\mathrm{ET}_{\mathrm{P}}$ which is in good agreement with the USEB method. Results are similar if VPD ORC and ORCHIDEE's $r_{\mathrm{a}}$ (case 6) are used. In both cases, the difference compared with ORCHIDEE's computation is below $20 \%$ in most parts of the world. These are the configurations of the FAO's equation that best match the USEB method globally. It is notable that case 3 provides estimates which are closer to the USEB method concerning certain arid regions; however, this is due to the overestimation of the FAO's VPD.

In summary, both $\mathrm{ET}_{\mathrm{P}} \mathrm{USEB}$ and $\mathrm{ET}_{\mathrm{P} \text { Milly provide similar }}$ results, confirming the idea that using $T_{\mathrm{S}}$ leads to an overestimation of potential evaporation. $\mathrm{ET}_{\mathrm{P}}$ USEB and $\mathrm{ET}_{\mathrm{P} F A O}$ are different due to certain assumptions made in the derivation of the FAO's equation, such as the treatment of the atmospheric stability, as discussed above. ORCHIDEE's $r_{\text {a }}$ provides a more detailed characterization of the surface and a better description of the atmospheric stability. When used in FAO's equation, the differences with the USEB method are reduced by more than $50 \%$ in some regions. The gradient used in the bulk formula, as well as the VPD $\mathrm{ORC}_{\text {are lower }}$ than FAO's approximation of the VPD, which is known to be overestimated in arid regions. Globally, the combined effect of the VPD ${ }_{\mathrm{ORC}}$ and the LSM's $r_{\mathrm{a}}$ (case 6), followed by that of the gradient and the LSM's $r_{\mathrm{a}}$ (case 4), provide the closest match to the $\mathrm{ET}_{\mathrm{P}}$ estimates yielded by the USEB method.

\subsection{Sensitivity of physically based ETP estimates to climate change}

This section analyses the sensitivity of estimated $\mathrm{ET}_{\mathrm{P}}$ to climate change, as simulated by the IPSL model for the A2 scenario. Special attention is paid to the USEB method and the FAO's reference equation because they are based on robust equations and represent the two families of approaches by which $\mathrm{ET}_{\mathrm{P}}$ estimations are made. This study is performed after analysing the causes of the different behaviours shown by both formulations (see Sect. 3.1). The Priestley-Taylor and Rohwer approximations have also been studied, in the next section, to analyse their sensitivity to the evolution of atmospheric conditions expected in a changing climate.

Climate change is driven by an increase in greenhouse gases which leads to higher incoming long-wave radiation, resulting in warmer surface and air temperatures. This, added to a lower diurnal amplitude of surface temperature, will affect both the VPD and the gradients between the surface and the atmosphere. Although rainfall and actual evaporation will experience changes as well, they are only expected to affect $\mathrm{ET}_{\mathrm{P}}$ in an indirect way.

The linear dependence of $\mathrm{ET}_{\mathrm{P}}$ on the VPD/humidity gradient and its inverse relation with the $r_{\mathrm{a}}$ are two common characteristics shared by ORCHIDEE's ET $\mathrm{P}_{\mathrm{P}}$ methodologies and FAO's equation. However, while the $R_{\mathrm{n}}$ is considered through the gradient computation in the LSM, it is an additive factor to the VPD in the FAO's equation. Climate change modifies several variables that are important for the estimation of $\mathrm{ET}_{\mathrm{P}}$, namely, (i) the $r_{\mathrm{a}}$, (ii) the $\mathrm{VPD} /$ humidity gradient, and (iii) the $R_{\mathrm{n}}$. For this reason these variables have been analysed in order to evaluate their impact on ETP. Figure 2 shows the trends which are statistically significant in percentage per decade.

The impact of climate change on wind speed directly affects the $r_{\mathrm{a}}$ as used in FAO. It is shown in Fig. 2a, where $r_{\mathrm{a}}$ 's trends are driven by the wind speed. Fig. $2 \mathrm{~b}$ shows the trends in ORCHIDEE's $r_{\mathrm{a}}$, which is impacted by climate change by way of the wind speed and the atmospheric stability. Because of this additional dependence, it shows a stronger and more diverse response to climate change, yielding trends which range from $-20 \%$ to $20 \%$ per decade. In contrast to FAO's equation, ORCHIDEE's $r_{\mathrm{a}}$ displays stronger negative trends, which can induce increases of $\mathrm{ET}_{\mathrm{P}}$. Therefore, it has to be noted that even in regions where the trend in $r_{\mathrm{a}}$ is not statistically significant, it can still impact $\mathrm{ET}_{\mathrm{P}}$.

Of the three sets of variables considered, the VPD and the bulk formula's gradient show a systematic increase over the world, as seen in Fig. 2c and d, just as the ETP. A similar behaviour is shown by USEB's gradient in Fig. 2e, which shows a general positive trend for most continental surfaces, but shows negative ones in some mountainous regions. The trend coherence shown between the $\mathrm{ET}_{\mathrm{P}}$ and the VPD/humidity gradient, is supported by the spatial correlation between them, which is 0.54 for the FAO's case and 0.61 

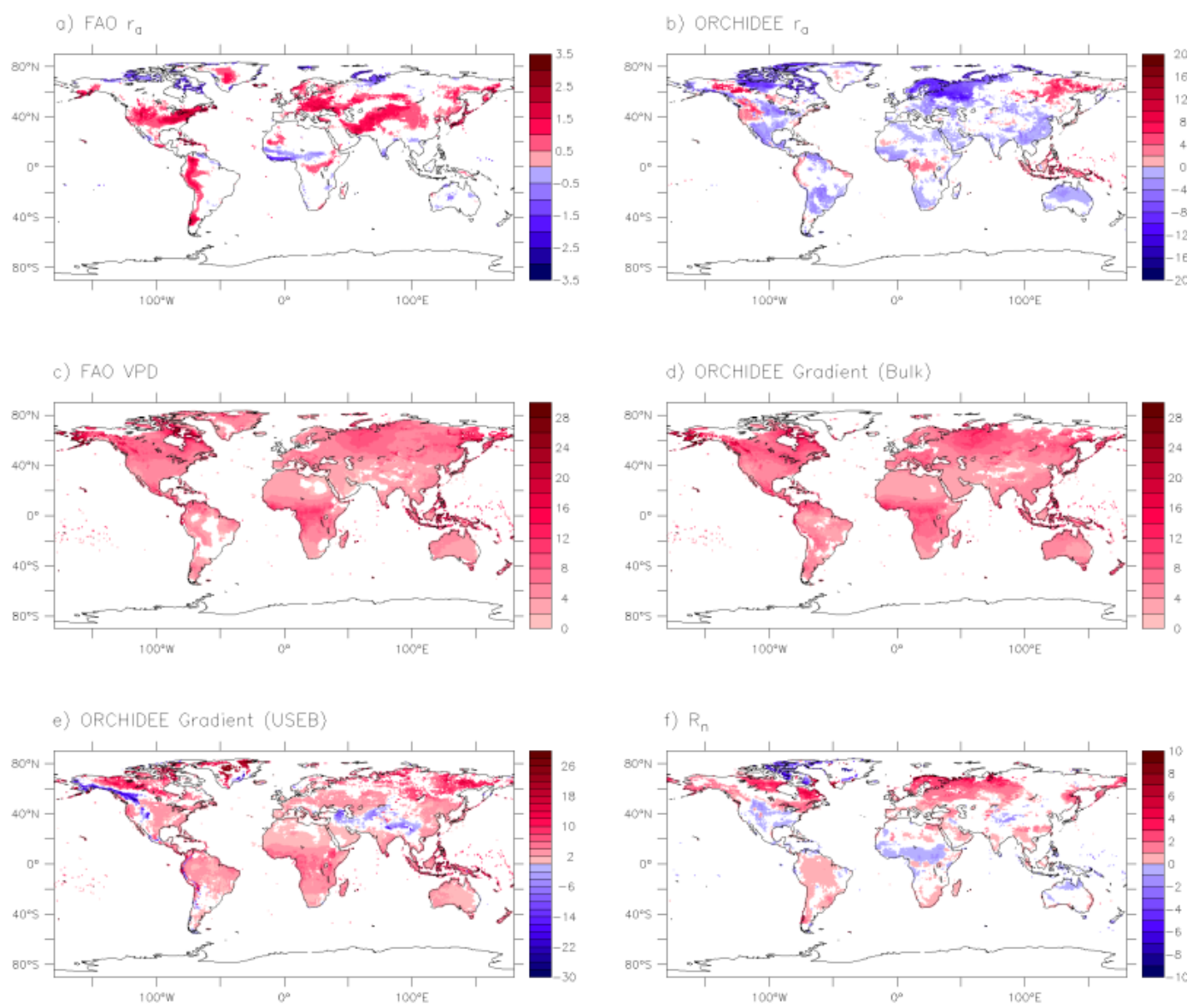

Fig. 2. Significant trends showing the increasing or decreasing $\%$ per decade for the aerodynamic resistance $\left(r_{\mathrm{a}}\right)$, the VPD, the humidity gradient, and the net radiation $\left(R_{\mathrm{n}}\right)$, regarding the IPSL A2 scenario and the different formulations. The blank areas correspond to regions where no significant trends have been found.

for USEB's. Spatial correlation was also computed between the $\mathrm{ET}_{\mathrm{P}}$ and $r_{\mathrm{a}}$, obtaining weaker relations. These reasons, as well as the fact that there is a linear dependence between $\mathrm{ET}_{\mathrm{P}}$ and VPD/humidity gradient, prove that these are the dominant terms in the trend seen for $\mathrm{ET}_{\mathrm{P}}$ for the climate change scenario we are considering.

Finally, the sensitivity of the net radiation has also been studied, because it determines the energy available at the surface for evaporation. ORCHIDEE's computation of $\mathrm{ET}_{\mathrm{P}}$, FAO's reference equation, and Priestley-Taylor's equation use the same radiation dependence. The trends in $R_{\mathrm{n}}$, shown in Fig. 2f, are positive in most cases as a direct consequence of an increase in greenhouse gases (Philipona and Dürr, 2004).

Figure 3a shows a significant increase of $\mathrm{ET}_{\mathrm{P}}$ over the entire globe (up to $8 \%$ per decade), computed with the USEB method. Based on the discussion above regarding the parameters it depends on, we conclude that it is essentially driven by the humidity gradient.

In order to compare the trends obtained for the various estimates of $\mathrm{ET}_{\mathrm{P}}$ with that of USEB's, the difference in trends as $\%$ of the value yielded by the USEB method has been diagnosed. Therefore, Fig. $3 \mathrm{~b}$ to e display differences in $\%$ of $\%$ per decade. This information is also detailed for the selected regions and the methodologies chosen to compute $\mathrm{ET}_{\mathrm{P}}$ in Table 4. The $\mathrm{ET}_{\mathrm{P}}$ computed using the bulk formula has also been considered in the sensitivity study, and thus included in Table 4.

In addition to the fact that $\mathrm{ET}_{\mathrm{P} \text { Milly }}$ provides estimates which are in good agreement with the USEB method (see Sect. 3.1), the similarity in trends between the two methods indicates that their sensitivities are also comparable (see Fig. 3b). The bulk formula overestimates ETP's sensitivities, because it uses $T_{\mathrm{S}}$ in its computation without applying a correcting factor.

Compared with the case 1 defined for the FAO's reference equation, the USEB method provides higher trends and thus higher sensitivity to climate change, as shown in Fig. 3c. For example, a difference of $54 \%$ is found over part of the region defined for Australia. This means that if the USEB method has an increase of $2.45 \%$ per decade, FAO's trend is only $1.13 \%$ per decade. Since the $\mathrm{ET}_{\mathrm{P}}$ values provided by 

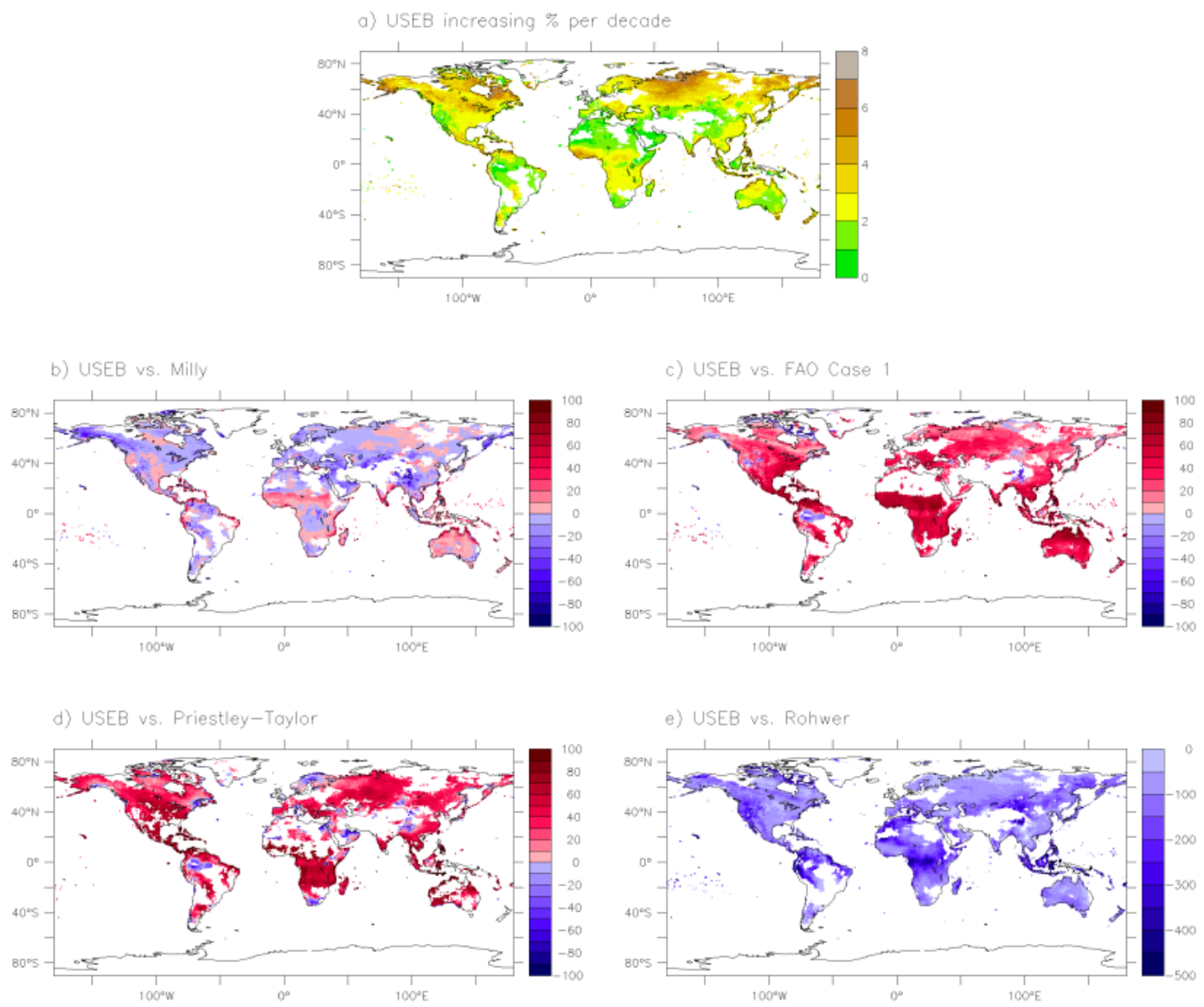

Fig. 3. The USEB method's ET $\mathrm{P}_{\mathrm{P}}$ significant trend showing the increasing $\%$ per decade (a). Differences, given in $\%$ of percent change per decade, between the USEB and Milly methods (b), between the USEB method and FAO's case 1 (c), and between the USEB method and the approximations of Priestley-Taylor and Rohwer ( $\mathbf{d}$ and $\mathbf{e}$ ). The blank areas correspond to regions where no significant trends have been found.

the two formulations differ (see Table 3), these percentages correspond to increases of 0.33 and $0.06 \mathrm{mmd}^{-1}$ per decade for the USEB method and the FAO's equation, respectively. Therefore, it must be emphasised that a difference of an order of magnitude can result between the two methodologies.

Table 4 shows that the differences are reduced when ORCHIDEE's $r_{\mathrm{a}}$ is used in the FAO's equation (cases 3, 4 and 6) in all regions except the Amazon Basin. This implies that considering atmospheric stability generally amplifies ETp's trends. Therefore, even though $r_{\mathrm{a}}$ may not drive a global ET $\mathrm{P}$ trend, it does amplify or decrease it. For instance, Fig. 3c shows that the difference in trends between ETP USEB and $\mathrm{ET}_{\mathrm{P} F A O}$ is higher in the north than in the south of Australia. Cases 1 and 3 were compared and FAO case 1 has a difference in trends of $1 \%$ between the northern and southern Australian regions, while if the atmospheric stability simulated by ORCHIDEE is taken into account (case 3), this difference rises to $38 \%$. Therefore, the VPD/humidity gradient drives the trend in $\mathrm{ET}_{\mathrm{P}}$ and the spatial variation of $r_{\mathrm{a}}$ produces the contrast shown by the USEB method and not by the FAO's method.

Comparing case 1 with cases 2 and 5 in Table 4, the sensitivity of $\mathrm{ET}_{\mathrm{P}}$ increases when VPD $\mathrm{ORC}_{\mathrm{O} C}$ or ORCHIDEE's gradient are used in the FAO's equation. This implies that the FAO's estimation of the VPD is less sensitive to climate change than VPD ${ }_{\text {ORC }}$ and ORCHIDEE's gradient.

As found for the reference period, the combined effect of ORCHIDEE's humidity gradient or the VPD $\mathrm{ORC}$ with $r_{\mathrm{a}}$ (FAO's cases 4 and 6), provides trends which are in good agreement with USEB's. For the Amazon region, where no strong trends were found regarding the VPD and $r_{\mathrm{a}}$, no significant difference is expected between the two methodologies, as shown in Table 4.

This study has been performed focusing on annual mean $\mathrm{ET}_{\mathrm{P}}$, but, the analysis has also been carried out in the Sahelian region for the humid and arid seasons. No fundamental difference has been found at the seasonal scale and thus have not been shown above. The VPD and humidity gradient are confirmed to be the key parameters that drive the positive 
Table 4. Significant increases of $\mathrm{ET}_{\mathrm{P}}$ are given in \% per decade. Their relative changes compared to the USEB method are expressed as a \%: $\left(\frac{\text { USEB-Method }}{\text { USEB }}\right) 100$.

\begin{tabular}{|c|c|c|c|c|c|c|c|c|c|}
\hline \multicolumn{10}{|c|}{$\mathrm{ET}_{\mathrm{P}}$ sensitivity study for the future scenario } \\
\hline \multicolumn{2}{|c|}{ Method } & \multicolumn{3}{|c|}{$\mathrm{ET}_{\mathrm{P}}$ change $(\%$ per decade $)$} & \multicolumn{5}{|c|}{ Trend difference to USEB $(\%)$} \\
\hline & & Australia & Sahel & $\begin{array}{l}\text { Central } \\
\text { Europe }\end{array}$ & $\begin{array}{c}\text { Amazon } \\
\text { Basin }\end{array}$ & Australia & Sahel & $\begin{array}{l}\text { Central } \\
\text { Europe }\end{array}$ & $\begin{array}{r}\text { Amazon } \\
\text { Basin }\end{array}$ \\
\hline \multirow[t]{3}{*}{ ORCHIDEE } & USEB & 2.45 & 1.85 & 2.05 & 1.24 & & & & \\
\hline & Milly & 2.1 & 1.62 & 2.26 & 1.4 & 14 & 12 & -10 & -13 \\
\hline & Bulk & 4.9 & 4.36 & 5 & 3.61 & -100 & -136 & -144 & -191 \\
\hline \multirow[t]{6}{*}{ FAO } & Case 1 & 1.1 & 0.57 & 1.31 & 1.05 & 55 & 69 & 36 & 15 \\
\hline & Case 2 & 1.45 & 0.8 & 1.63 & 1.1 & 41 & 57 & 20 & 11 \\
\hline & Case 3 & 2.04 & 1.36 & 2.01 & 1.01 & 17 & 26 & 2 & 19 \\
\hline & Case 4 & 2.51 & 1.69 & 2.39 & 1.46 & -2 & 9 & -17 & -18 \\
\hline & Case 5 & 1.11 & 0.64 & 1.32 & 1.05 & 55 & 65 & 36 & 15 \\
\hline & Case 6 & 2.06 & 1.46 & 2.04 & 1.04 & 16 & 21 & 0 & 16 \\
\hline \multirow[t]{2}{*}{ Simplif. Approx. } & $\begin{array}{l}\text { Priestley- } \\
\text { Taylor }\end{array}$ & 0.43 & 0.44 & 1.59 & 1.1 & 82 & 76 & 22 & 11 \\
\hline & Rohwer & 4.05 & 3.61 & 4.01 & 2.56 & -65 & -95 & -96 & -106 \\
\hline
\end{tabular}

trend of $\mathrm{ET}_{\mathrm{P}}$. Their sensitivities increased during the humid season.

The impact of the approximations that the FAO's method uses to compute the VPD and $r_{\mathrm{a}}$ on their climate change signals as well as on ETP's climate change signal has been analysed in this section. Both parameters produce trends that are underestimated if compared with those computed in ORCHIDEE. Consequently, ETP's sensitivity is reduced when computed with the FAO's method.

Deficiencies found in the FAO's ETP sensitivity to climate change also apply to FAO's $\mathrm{ET}_{\mathrm{O}}$. The reason is that both the VPD and $r_{\mathrm{a}}$ are used in its estimation, as shown in Eq. (9). During our study, we have analysed the sensitivity of FAO's $\mathrm{ET}_{\mathrm{o}}$ to climate change. The same analysis has been performed for an empirical formulation developed from FAO's methodology. This is the Hargreaves' method, which approximates $\mathrm{ET}_{\mathrm{o}}$ by the air temperature (Hargreaves and Samani, 1982, 1985). Differences between their trends were found to be under $12 \%$ for all of the four regions selected, except the Amazon Basin (where no significant trend was provided by Hargreaves' method). The equivalence in trends highlights the need to take into account the impact of the assumptions made on the $r_{\mathrm{a}}$ and the VPD, not only because of their effect on FAO's $\mathrm{ET}_{\mathrm{O}}$ sensitivity, but also on that of further derived simplified formulations.

Another issue to be taken into account is the fact that GCMs may have significant errors and thus estimates of ETP can have a strong bias. However, even though they might be affected by systematic biases, the estimate of the trend will include aspects of climate change in the wind speed and turbulence that can not be integrated into the more classical estimates of ETP's daily equation. So it might be more suitable to unbias $\mathrm{ET}_{\mathrm{P}}$ estimates originating in GCMs, than the variables needed to compute it by means of FAO's equation.

\subsection{Sensitivity of empirical ET $_{\mathbf{P}}$ estimates to climate change}

The two empirical approximations (Priestley-Taylor and Rohwer) show different behaviours regarding their sensitivity to climate change. None of them considers changes in atmospheric stability, which is a key aspect in the FAO formulation as it has shown to amplify ETP's trends for a changing climate. Rohwer's equation shows higher trends than the USEB method, in some cases by more than $400 \%$, as shown in Fig. 3e. The cause is that $\mathrm{ET}_{\mathrm{P}}$ is approximated by only keeping the dependence on the wind speed and the VPD, which provides positive trends from 0 to $30 \%$ per decade, shown in Fig. 2c, and has been identified as the driving variable of ETP's trends. On the other hand, the Priestley-Taylor method shows a positive difference in trends in Fig. 3d, which implies that it has a lower sensitivity to climate change than the USEB method. Its trend is driven by the $R_{\mathrm{n}}$ and provides lower/higher trends than FAO's equation in arid/humid regions. This result is in good agreement with (Weedon et al., 2011) as well as (Kingston et al., 2009), who found that the lack of dependence on VPD in this formulation is significant in arid regions.

McVicar et al. (2012) suggests that when dealing with climate change, the impact of four primary meteorological variables (wind speed, atmospheric humidity, net radiation and air temperature) should be considered to better understand $\mathrm{ET}_{\mathrm{P}}$. Because the empirical methods do not include the complex interaction between the key variables in the $\mathrm{ET}_{\mathrm{P}}$ 
estimates $\left(R_{\mathrm{n}}, r_{\mathrm{a}}, \mathrm{VPD} /\right.$ gradient $)$ they are not able to reproduce the trends found with the more physically based estimates. Furthermore, they are also regionally constrained. For instance, Fig. $2 \mathrm{f}$ shows that the $R_{\mathrm{n}}$ has a high impact in the Amazonian region and the approximation that provides the closest sensitivity to the USEB method is that of PriestleyTaylor, which is radiation-based. Rohwer's method does not consider the net radiation; as a result, its trend differs by $106 \%$ from the USEB's trend in that region.

As discussed in Sect. 3.1, the values analysed from Table 4 show results which are representative of the general behaviour of the trends provided by the different methodologies.

Summing up the sensitivity study performed for $\mathrm{ET}_{\mathrm{P}}$ estimates, the VPD/humidity gradient has been identified as the key parameter that drives the increase of $\mathrm{ET}_{\mathrm{P}}$ for the IPSL A2 climate change scenario. The stability assumption made by FAO is probably an oversimplification which leads to a lower sensitivity than the USEB method. The two empirical estimations of $\mathrm{ET}_{\mathrm{P}}$ show different sensitivity to climate change, depending on the region selected and the parameters used to compute $\mathrm{ET}_{\mathrm{P}}$, and none of them seem compatible with the physical estimates.

\section{Summary and conclusions}

The study detailed in this paper consisted of three stages. In the first one, a new method to compute Penman-Monteith's potential evaporation $\left(E T_{P}\right)$ through an unstressed surfaceenergy balance (USEB) was implemented in the ORCHIDEE land surface model. During the second stage, a comparison between several methodologies was performed for the current climate. These are the USEB method, the previous estimation implemented in ORCHIDEE (Milly, 1992) and FAO's reference evapotranspiration equation. In the third stage, ETP's sensitivity to climate change was studied for the same methodologies, as well as for two empirical approximations (Priestley-Taylor and Rohwer). The sensitivity study was extended to ETP's parameters in order to identify the key ones for a changing climate.

The USEB method is based on Budyko's hypothesis and thus is a more robust equation than the FAO's recommendation of the Penman-Monteith method (Allen et al., 1998). The FAO's equation has been developed for a reference surface and assumes a neutral atmosphere. In order to adapt it, the aerodynamic resistance $\left(r_{\mathrm{a}}\right)$ as proposed by ORCHIDEE has been introduced in the FAO's equation. Furthermore, the humidity gradient (used in ORCHIDEE's estimations) and the VPD, also computed in the land surface model, have been used in the FAO's equation as well.

The results have shown that USEB and Milly's estimations are in good agreement regarding $\mathrm{ET}_{\mathrm{P}}$ 's global average as well as its sensitivity to climate change. However, the $\mathrm{ET}_{\mathrm{P}}$ found by USEB differs from the $\mathrm{ET}_{\mathrm{P}}$ underlying the $\mathrm{FAO}$ reference equation. The USEB method produces higher estimates of $\mathrm{ET}_{\mathrm{P}}$ and higher contrast in annual spatial variance, as well as a higher climate change signal. Significant differences have also been found in the amplitude of the trends provided by the empirical approximations and within their spatial structures. The sensitivity study done of $\mathrm{ET}_{\mathrm{P}}$ 's parameters has revealed a similar behaviour between FAO's VPD approximation and ORCHIDEE's VPD and humidity gradient, the last two being more sensitive to climate change. FAO's scheme for the aerodynamic resistance has been found to reduce the spatial structures and the global average of ETP's trends when compared to ORCHIDEE's methods. Correlation studies between the $\mathrm{ET}_{\mathrm{P}}$ and the evolution of these parameters have shown strong spatial relations between the VPD/humidity gradient and the atmospheric water demand. Such relations were not found for the aerodynamic resistance.

It can be concluded from the study that the consistency of the USEB and Milly methods shows that they are reasonable estimates of Penman-Monteith's ETP estimation. Although the USEB method implies more computational time, it has fewer assumptions than Milly's correction and should thus be more robust. Both of them agree that the $\mathrm{ET}_{\mathrm{P}}$ obtained through the bulk formula is overestimated, because of a humidity gradient which is exaggerated through the usage of the actual surface temperature instead of the virtual temperature. It can also be concluded that the sensitivity of the ET $_{P}$ assumed in FAO's equation underestimates its sensitivity to climate change when compared to the USEB and Milly methods. As for the empirical approximations, the simplifications made in the $\mathrm{ET}_{\mathrm{P}}$ estimation neglect processes that play an important role when the climate changes. Concerning $\mathrm{ET}_{\mathrm{P}}$ 's key parameters, it was found that the assumption of neutral stability conditions is one of the weakest made in FAO's formulation. The humidity gradient and the VPD have been identified as the driving variables for the estimate of $\mathrm{ET}_{\mathrm{P}}$ carried out with the USEB and FAO's methodologies, respectively.

Agronomic and hydrological models which need to estimate actual evaporation will use one of the ET $\mathrm{P}_{\mathrm{P}}$ estimations presented above. They will then apply a surface resistance in order to take into account the vegetation or soil capacity to provide water for evaporation. When these models are then applied in a climate change scenario, attention has to be paid to the sensitivity of the ETP formulation underlying the evaporation model. This paper has shown that various methods developed to estimate $\mathrm{ET}_{\mathrm{P}}$ do not provide equivalent estimates nor do they provide comparable sensitivities to climate change. The estimation of $\mathrm{ET}_{\mathrm{P}}$ in the LSM is the method that contains most of the physical processes that we believe are important for determining the climate change impact on $\mathrm{ET}_{\mathrm{P}}$. These processes have been identified and in some cases, found to be missing in other $\mathrm{ET}_{\mathrm{P}}$ estimations.

For all these reasons, we hypothesise that the USEB and Milly's methods not only provide a good estimate for current climate, but also produce a realistic sensitivity of $\mathrm{ET}_{\mathrm{P}}$ to 
climate change. Therefore, we suggest that they should be regarded as an essential addition to climate models and propose to keep ETP as a standard output of any IPCC simulation.

Potential evaporation is a key variable in the climate system, because it represents the interactions between the surface and the atmosphere. It should provide a good view into the impact of climate change on surface processes, since it depends on variables like temperature, net radiation, humidity and wind speed.

Different methods have been developed to estimate its value and we believe that they should not only be tested for accurate representation of current climate, but its sensitivity to climate change should be considered too. In addition, regarding climate change studies, we recommend to unbias modelled $\mathrm{ET}_{\mathrm{P}}$ estimates, instead of re-estimating them from basic atmospheric variables and simplified equations.

Acknowledgements. We gratefully acknowledge the helpful comments of Agnès Ducharne, Filipe Aires, Kaicun Wang, Eleanor Blyth, Tim McVicar, Kerstin Stahl, and Laura Kerber. The computer time was provided by the Institut du Développement et des Resources en Informatique Scientifique (IDRIS). This research was undertaken within the EU FP6 project WATCH, Water and Global Change, (Contract 036946).

Edited by: K. Stahl

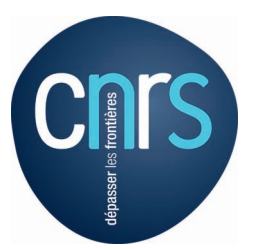

The publication of this article is financed by CNRS-INSU.

\section{References}

Allen, R. G., Pereira, L. S., Raes, D., and Smith, M.: Crop Evapotranspiration - Guidelines for Computing Crop Water Requirements, FAO Irrigation and Drainage Paper No. 56, Rome, 1998.

Budyko, M. I.: Heat Balance of the Earth's Surface, Gidrometeoizdat, Leningrad, 1956.

Campbell, R. B. and Phene, C. J.: Estimating potential evapotranspiration from screened pan evaporation, Agr. Meteorol., 16, 343-352, 1976.

de Bruin, H. A. R., Trigo, I. F., Jitan, M. A., Temesgen Enku, N., van der Tol, C., and Gieske, A. S. M.: Reference crop evapotranspiration derived from geo-stationary satellite imagery: a case study for the Fogera flood plain, NW-Ethiopia and the Jordan Valley, Jordan, Hydrol. Earth Syst. Sci., 14, 2219-2228, doi:10.5194/hess-14-2219-2010, 2010.

de Rosnay, P. and Polcher, J.: Modelling root water uptake in a complex land surface scheme coupled to a GCM, Hydrol. Earth Syst. Sci., 2, 239-255, doi:10.5194/hess-2-239-1998, 1998.

de Rosnay, P., Polcher, J., Bruen, M., and Laval, K.: Impact of a physically based soil water flow and soil-plant interaction representation for modeling large-scale land surface processes, J. Geophys. Res., 107, 4118, doi:10.1029/2001JD000634, 2002.
Hargreaves, G. H. and Samani, Z. A.: Estimation of potential evapotranspiration, Journal of Irrigation and Drainage Division, Proc. Am. Soc. Civil Eng., 108, 223-230, 1982.

Hargreaves, G. H. and Samani, Z. A.: Reference Crop Evapotranspiration from Temperature, Appl. Eng. Agr., 1, 96-99, 1985.

Hobbins, M. T., Dai, A., Roderick, M. L., and Farquhar, G. D.: Revisiting the parameterization of potential evaporation as a driver of long-term water balance trends, Geophys. Res. Lett., 35, L12403, doi:10.1029/2008GL033840, 2008.

Kingston, D. G., Todd, M. C., Taylor, R. G., Thompson, J. R., and Arnell, N. W.: Uncertainty in the estimation of potential evapotranspiration under climate change, Geophy. Res. Lett., 36, L20403, doi:10.1029/2009GL040267, 2009.

Kohler, M. A., Nordenson, T. J., and Fox, W. E.: Evaporation from pans and lakes, Weather Bureau Research Paper 38, US Department of Commerce, Washington, 1955.

Krinner, G., Viovy, N., de Noblet-Ducoudré, N., Ogée, J., Polcher, J., Friedlingstein, P., Ciais, P., Sitch, S., and Prentice, I. C.: A dynamic global vegetation model for studies of the coupled atmosphere-biosphere system, Global Biogeochem. Cy., 19, GB1015, doi:10.1029/2003GB002199, 2005.

Louis, J.-F.: A parametric model of vertical eddy fluxes in the atmosphere, Bound.-Lay. Meteorol., 17, 187-202, 1979.

Makkink, G. F.: Testing the Penman Formula by means of lysimeters, J. Inst. Water Eng., 11, 277-288, 1957.

Manabe, S.: Climate and the ocean circulation, 1. the atmospheric circulation and the hydrology of the earth's surface, Mon. Weather Rev., 97, 739-774, 1969.

McMahon, T. A., Peel, M., C., Lowe, L., Srikanthan, R., and McVicar, T. R.: Estimating actual, potential, reference crop and pan evaporation using standard meteorological data: a pragmatic synthesis, Hydrol. Earth Syst. Sci., 17, 1331-1363, doi:10.5194/hess-17-1331-2013, 2013.

McVicar, T. R., Roderick, M. L., Donohue, R. J., and Van Niel, T. G.: Less bluster ahead? Overlooked ecohydrological implications of global trends of terrestrial near-surface wind speeds, Ecohydrology, 5, 381-388, doi:10.1002/eco1298, 2012.

Milly, P. C. D.: Potential evaporation and soil moisture in general circulation models, J. Climate, 5, 209-226, 1992.

Monteith, J. L.: Evaporation and surface temperature, Q. J. Roy. Meteor. Soc., 107, 1-27, 1981.

Parry, M., Arnell, N., Berry, P., Dodman, D., Frankhauser, S., Hope, C., Kovats, S., Nicholls, R., Satterthwaite, D., Tiffin, R., and Wheeler, T.: Assessing the Costs of Adaptation to Climate Change, A Review of the UNFCCC and Other Recent Estimates, Grantham Institute for Climate Change, Imperial College London, UK, 2009.

Penman, H. L.: Natural evaporation from open water, bare soil and grass, P. R. Soc. Ldn., 193, 120-145, 1948.

Philipona, R. and Dürr, B.: Greenhouse forcing outweighs decreasing solar radiation driving rapid temperature rise over land, Geophys. Res. Lett., 31, L22208, doi:10.1029/2004GL020937, 2004.

Piani, C., Weedon, G. P., Best, M., Gomes, S. M., Viterbo, P., Hagemann, S., and Haerter, J. O.: Statistical bias correction of global simulated daily precipitation and temperature for the application of hydrological models, J. Hydrol., 395, 199-215, 2010.

Priestley, C. H. B. and Taylor, R. J.: On the assessment of surface heat flux and evaporation using large-scale parameters, Mon. Weather Rev., 100, 81-92, 1972. 
Rohwer, C.: Evaporation from free water surface, USDA Technical Bulletin, 271, 127, 1-96, 1931.

Walter, I. A., Allen, R. G., Elliot, R., Itenfisu, D., Brown, P., Jensen, M. E., Mecham, B., Howell, T. A., Snyder, R., Eching, S., Spofford, T., Hattendorf, M., Martin, D., Cuenca, R. H., and Wright, L.: The ASCE standardized reference evapotranspiration equation, Task Committee on Standardization of Reference Evapotranspiration Final Report, ASCE Environmental and Water Resources Institute, Reston, VA, 2005.

Wang, K. and Dickinson, R. E.: A review of global terrestrial evapotranspiration: observation, modeling, climatology, and climatic variability, Rev. Geophys., 50, RG2005, doi:10.1029/2011RG000373, 2012.
Weedon, G. P., Gomes, S., Viterbo, P., Shuttleworth, W. J., Blyth, E., Österle, H., Adam, J. C., Bellouin, N., Boucher, O., and Best, M.: Creation of the WATCH forcing data and its use to assess global and regional reference crop evaporation over land during the twentieth century, J. Hydrometeorol., 12, 823-848, 2011.

$\mathrm{Xu}$, C.-Y. and Singh, V. P.: Cross comparison of empirical equations for calculating potential evapotranspiration with data from Switzerland, Int. Ser. Prog. Wat. Res., 16, 197-219, 2002. 